\title{
Para seguir los rastros de los
movimientos a
inicios de la segunda
década del siglo $X X \mathrm{XI}$ rastros de los
movimientos a
inicios de la segunda
década del siglo $X X \mathrm{XI}$
} Introducción

Los movimientos sociales de inicios de la segunda década del siglo XXI en México y en el mundo implican novedosas modalidades que requieren de un tra-

Los elementos analíticos para estudiar los movimientos sociales se han quedado cortos para comprender los movimientos que han irrumpido en la segunda década del siglo XXI. Han ido apareciendo algunas teorizaciones que confirman que esta temática prosigue abierta al debate. Las principales tendencias desde las cuales se han ensayado acercamientos a los movimientos de indignados son revisadas. Proponemos un conjunto conceptual para indagar los movimientos de los de abajo. Llamamos la atención del zapatismo como movimiento fundante de la nueva dinámica en el que encontramos la búsqueda de la demoeleuthería, y destacamos su actuación en torno a la tragedia de Ayotzinapa. Planteamos como pista tratar de atisbar la configuración de movimientos emancipa-

torios

Palabras clave: movimientos sociales, los de abajo, indignación, zapatistas, demoeleuthería.

- Profesor-investigador del CUCSH de la Universidad de Guadalajara exodus_gdl@hotmail.com • Profesor-investigador del CIESASOccidente

jalonso@ciesas.edu.mx ـ tamiento que no se quede en los viejos moldes. El año 2011 vio la emergencia de la primavera árabe (sobre todo en Túnez y Egipto), el movimiento de indignados en España, Grecia, Islandia, Israel y Gran Bretaña y de los estudiantes chilenos (que han mantenido una lucha que va desde entonces y permanece en 2014). Mención aparte merece el movimiento de los Ocupa en Estados Unidos, el cual tuvo una aparición emblemática en Nueva York pero se regó por numerosas ciudades de ese país. En México del 2011 se creó el pujante movimiento por la paz, y en 2012 apareció el \#Yosoy132. En ese mismo país, un año después se fortaleció el movimiento magisterial y en Brasil fue relevante el movimiento que inició con la protesta por el transporte y que se extendió debido a otros tantos problemas acumulados. 
En México de 2014 el anudamiento del Estado y el narcotráfico propició el surgimiento de un relevante movimiento en que los pueblos buscaron crear formas de autodefensa; también se protestó por la soberbia y la crueldad de los de arriba; esos que recientemente han pretendido banalizar el mal ante el ataque a los estudiantes normalistas. Explotó el hartazgo de los terribles crímenes, y lo hizo como un reclamo por el regreso de los desaparecidos con vida. Ese movimiento se extendió por todo México y por el mundo. Los de abajo ${ }^{1}$ ante la corrupción y la impunidad respondieron con compasión y solidaridad hacia las víctimas, reclamando fuerte por una auténtica justicia y por un cambio fundamental en materia de derechos humanos para impedir los crímenes de lesa humanidad. También en 2014 surgió un movimiento estudiantil en pos de la autonomía, y en Hong Kong los jóvenes demandaron democracia.

Las novedades están en el modo en que gran parte de estos movimientos ha surgido: por convocatorias en las redes sociales que se fueron haciendo "virales", ampliamente contagiosas; protestas que no se limitaron a lo virtual, sino que

\footnotetext{
I. El término "los de abajo" proviene de una novela de Mariano Azuela que empezó a escribir por partes a mediados de la segunda década del siglo XX sobre la mirada que permite apreciar la complejidad de la revolución mexicana. Ha tenido muchas ediciones, una de ellas en el Fondo de Cultura Económica, México, 1972. Posteriormente Pablo González Casanova prologó dos libros colectivos acerca de la democracia de los de abajo (Alonso y Ramírez, 1996 y 1997) en el que expresaba que desde abajo y de los de abajo eran dos expresiones parecidas pero distintas. $\mathrm{Si}$ bien ambas comprendían un proyecto de democracia con el pueblo, en el primer caso se acentuaba el deseo de construir la democracia desde abajo en todo el país, y en el segundo se ponía el acento en construir la democracia en las propias organizaciones del pueblo. Precisaba que el problema de fondo era que todos los movimientos de los de abajo planteaban demandas que afectaban los intereses creados y a las nuevas redes de poder de la globalización. Se pretendía que la democracia planetaria tuviera traducciones reales de libertad, justicia y dignidad como lo planteaban los zapatistas chiapanecos (González Casanova, 1997). Los coordinadores de esos libros recalcaban que la democracia de los de abajo privilegiaba a los integrantes del pueblo. Se investigó como se vivía la democracia en emergentes movimientos populares de todo tipo en rechazo a toda expresión de autoritarismo. Ese abajo tenía que ver con las más diversas expresiones populares en contra de la dominación (Alonso y Ramírez, 1996 y 1997).
}

\section{0}


Para seguir los rastros de los movimientos a inicios de la segunda década del siglo XXI

llenaron calles, plazas, y tomaron edificios públicos; lo virtual y el cara a cara se complementaron. Otra situación destacable es que hubo voceros pero no líderes; no había jefes, y los de arriba no sabían con quiénes habría que negociar, cooptar o aislar. Existió un impulso horizontalista que se tradujo en un ejercicio del diálogo amplio, asambleario, con el cual se llegó a acuerdos. Muchas protestas iniciaron por el desempleo, los salarios insuficientes, las políticas de austeridad, la falta de servicios sociales; contra el autoritarismo y el abuso de las fuerzas policiales, contra el espectáculo de una democracia que no correspondía a su nombre, y por diversos malestares provocados por un capitalismo agraviante. De las calles pasó a los barrios, a las escuelas, a los centros laborales. No hubo una demanda central: se fueron expresando muchos malestares; se repudió a la clase política en general y se pidió una auténtica democracia; un clamor que no se trasladó a la arena electoral, sino que se tradujo en la creación de espacios de convivencia donde se habló, se debatió, se dialogó y se construyeron consensos respecto a acciones determinadas. Se trató de un flujo continuo de expresiones de muchos de los de abajo que estaban luchando por crear espacios propios y no aceptaban el capitalismo.

Aunado a lo anterior, durante todos estos años se ha consolidado y renovado el movimiento zapatista, el cual, ubicado en México pero con influencia mundial, desde hace mucho ha hecho ver que la confrontación se da entre un arriba que despoja y oprime y un abajo que es muy complejo, heterogéneo y diverso, pero crecientemente tendiente hacia lo que el zapatismo ha llamado el abajo a la izquierda y anticapitalista.

No obstante, no todos los movimientos tuvieron esas características y perduraron expresiones como las de los sindicalistas británicos, los cuales a finales de 2014 repudiaron las políticas de austeridad y exigieron mejores

Teoría y DEBATE No. 62 
salarios. ${ }^{2}$ Han existido y subsisten los movimientos sociales que podríamos llamar tradicionales. Entre ellos están los movimientos campesinos que vienen desde mucho tiempo atrás. El capitalismo, que con su acumulación originaria despojó a los campesinos de sus tierras, propició masas de desposeídos que solo tendrían su fuerza de trabajo, entre ellos surgieron grupos de inconformes que combatieron por la defensa de su tierra y por la restitución de la usurpada. Otros de los movimientos tradicionales son los obreros, cuyos miembros, ante lo duro de la explotación, han luchado por jornadas de trabajo menos onerosas, salarios dignos, prestaciones sociales y un conjunto de políticas sociales que favorezcan la situación obrera. Otros movimientos se han inscrito dentro de lo que se ha denominado movimientos revolucionarios, los cuales han buscado tomar el poder para desde él realizar los cambios sociales benéficos para la mayoría. Hay otros movimientos que podríamos inscribir en lo que Touraine planteó como el trípode de los mismos: identidad, organización y lucha por lo más significativo de la sociedad en turno (Touraine, 1987). No obstante, la identidad no es algo esencialista, puesto que hay muchas identidades en un solo individuo y estas sufren continuas mutaciones y desapariciones.

Después surgieron aquellos a los que se quiso nombrar nuevos movimientos sociales, que no eran clasistas, sino sectoriales y que reclamaban demandas más específicas relacionadas con el conjunto de la convivencia social: movimientos por la paz, movimientos de mujeres, de jóvenes, de estudiantes, de ecologistas, etc., ante lo cual se recalcó que muchos de ellos no tenían reclamos que se tradujeran materialmente, debido a que eran culturales. 
Para seguir los rastros de los movimientos a inicios de la segunda década del siglo XXI

En este artículo nos propusimos proseguir los planteamientos desarrollados en el libro Repensar los movimientos sociales (Alonso, 2013), en el cual se revisaron las principales discusiones en torno a los movimientos sociales y se realizó un tránsito del recuento de certezas a la formulación de dudas, para concluir en las incertidumbres en torno a la misma conceptualización de movimiento social. Sobre este libro hubo una crítica que apuntó como deficiencia el que las fuerzas rupturistas-constructivas no aparecieran unificadas y cohesionadas en estrategias comunes, que no se hiciera uso de los conceptos de clases, insurrecciones y revolución, sobre todo de este último, entendido en su acepción de movimiento integrador, dialéctico y holista, de revolución socialistacomunista total (Adame, 2013). Con todo, recordemos que existen no pocos agrupamientos que se distancian del modelo leninista para entablar nuevas búsquedas.

Otra reflexión a propósito de Repensar... se señaló que el libro destacó la complejidad y la dificultad de la respuesta a la pregunta cómo superar al capitalismo y su economía deshumanizada y depredadora. Una complejidad que incluía la visión del futuro: a qué sociedad se aspira y cómo alcanzarla. Y más todavía: en qué tipo de relaciones sociales y actitudes culturales actuales podría localizarse el germen de la nueva convivencia. A quien escribió esa segunda reseña le pareció que la conclusión más importante del libro en cuestión era que la esperanza del cambio estaba viva, aunque el propio término de movimientos sociales pareciera ser insuficiente para aprehender la compleja realidad de nuestros días (Fábregas, 2014).

El libro trató de cerrar todo un conjunto de planteamientos sobre los movimientos sociales, así como trató de comenzar a abrir una senda hacia pistas para entender los movimientos de inicios de la segunda década del siglo XXI. Atenderemos, entonces, las principales tendencias de interpretación que se han propuesto ante tales movimientos.

Teoría y DEBATE No. 62 
Diversas tendencias para tratar de entender a estos movimientos

Un primer acercamiento a estos movimientos muestra la fuerte crítica, rechazo y descalificación que provocaron. Por ejemplo, Bauman (2013) ve la expresión de multitudes como solidaridad explosiva y festiva que no invita sino a sincronizar el griterío, sin llegar a transformar las condiciones sociales. Sin embargo, el autor se queda en la superficie y no atisba lo que realmente se está moviendo debajo de estas manifestaciones, aunque sí es consciente de que si se diera un cambio en el modo de pensar desde abajo sería posible llegar a un mundo hospitalario. Bauman precisa que el éxito no está asegurado, por lo que se requieren paciencia y esperanza. Reflexiona que esto nos coloca otra vez ante la discusión sobre qué cambia a qué: si el modo de pensar al modo de actuar o el modo de actuar a las formas de pensar. Por nuestra parte, pensamos que se trata de algo complejo, no lineal sino dinámico e interactivo. Los nuevos movimientos tienden a desconfiar de los partidos y a buscar formas no jerárquicas de interacción. Si bien es cierto que esto ha sido visto como una trampa de la despolitización de la derecha para desacreditar la participación de los ciudadanos en la militancia partidaria, lo cual redunda en que se queden al cargo de los puestos públicos los políticos de siempre.

Se nos recuerda que Daniel Bensaïd advirtió que el descrédito sistemático de la forma partido resulta algo demagógico, pues aviva el cinismo estéril, el desinterés cívico y la indiferencia despolitizada al afirmar que todo está podrido y que cada uno se las ha de arreglar como pueda (Hernández, 2014). Žižek (2010) está de acuerdo en que la política antidemocrática busca la despolitización, y recuerda que la lucha política no es una discusión racional entre intereses múltiples, sino la lucha por hacer oír la propia voz, de ser reconocido como interlocutor legítimo. Se ha dicho que 
Para seguir los rastros de los movimientos a inicios de la segunda década del siglo XXI

aunque estos movimientos, paradójicamente, digan que están contra el neoliberalismo, se encuentran contagiados de él y le hacen el juego al sistema. La izquierda partidista aduce a que incitando el rechazo a la vía electoral, estos movimientos dejan la vía libre a la derecha neoliberal.

Sin embargo, no habría que caer en la trampa, ni la de la derecha ni la de la izquierda, porque ambas quieren meter en su juego a los ciudadanos, para que voten por 'el menos malo'. Hay otros derroteros y otras formas de hacer política que no necesariamente transitan por las viejas formas partidistas y estatistas. Quienes consideran que la toma del Estado es crucial para el cambio social también critican a los nuevos movimientos y les auguran fracaso en sus anhelos de cambio, debido a que no tienen la fuerza organizativa para derrotar a la fuerte derecha neoliberal. Se anuncia que se disiparán en su fragmentación. Y hay quienes apuntan a que los medios de comunicación, a lo sumo, nos permiten asomarnos a lo más epidérmico de las acciones disruptivas, desobedientes y no ven -u ocultantodo lo demás. Llaman la atención de que es importante ver ese conjunto de subjetividades originadas por diferentes dimensiones de la dominación. Algunos autores destacan que no se puede escapar de la fórmula partido, y que hay sectores de esos movimientos que impulsan nuevos partidos, como Podemos en España, o dinamizan partidos ya existentes, como Syriza en Grecia.

Se ha dicho que las movilizaciones construyen elites con perfiles tales que resultan inasequibles a las mayorías participantes, y que las asambleas más que un espacio liberador pueden volverse mercados políticos de pequeñas elites de poder (Moreno, 2014). No obstante, muchos observadores insisten en que se deberían compartir diagnósticos, pronósticos y motivaciones, pues existe el riesgo de que el poder aprenda a readaptarse a las grietas que generan estas redes (Yacubovich, 2013). De hecho, hay evidencias

Teoría y DEBATE No. 62 
de que en muchos movimientos han actuado provocadores (Rodríguez Araujo, 2014) y de que medios de comunicación y grupos empresariales han intentado apropiarse de los ropajes externos de estos nuevos movimientos para hacer aparecer cómo tales movilizaciones son manipuladas para mantener el statu quo o para revertir algunas tímidas reformas. No se debería olvidar que la figura del Estado estabiliza la concepción de un mundo jerarquizado, es legitimadora de un orden en que existe un arriba y un abajo, y que el objetivo central del poder es subordinar y domesticar la subjetividad rebelde (Tischler, 2013).

Otras tendencias intentan descubrir las potencialidades de dichos movimientos. En ellas se hace ver que los movimientos de inicios de la segunda década del siglo XXI comparten frustración y dignidad; que sus protestas no tienen demandas porque no quieren gobernar la sociedad, sino transformarla (Arditi, 2014). Hay quienes insisten en que los nuevos jóvenes iracundos forman parte de los nuevos movimientos globales; que el llamado Blak Block es una herramienta de acción que se traslada a otras protestas, pero que no constituye el corazón de esos movimientos. Se enfatiza que se trata de un descontento global y no coyuntural, que no estaría bien señalarlos como jóvenes "iracundos", sino como nuevos rebeldes que construyen ideas y prácticas para una sociedad alternativa; que no obstante sus no pequeñas limitaciones hablan de procesos y no de proyectos partidistas.

Los nuevos rebeldes proponen nuevas preguntas y las conversaciones sociales han ido cambiando. Sin embargo, persiste la duda de si por su falta de articulación podría señalárseles como insurgentes y revolucionarios (Calle, 2013). Sin mitificar el pasado, no hay que perder de vista una constante: la gente no cesa de rebelarse. Aquí conviene remitirse a Manuel Castells, quien en uno de sus escritos enfocó a las nuevas movilizaciones como redes de indigna- 
Para seguir los rastros de los movimientos a inicios de la segunda década del siglo XXI

ción y esperanza. Tal vez convendría señalar que se trata de esas novedosas redes que se fraguan tanto en lo virtual como en las acciones públicas, aceptando que no se trata de una discusión cerrada sino de una en curso, dado que el concepto movimientos sociales sigue siendo utilizado y debatido (Castells, 2012).

Cuando se dice que son movimientos de los de abajo, no es que todos los de abajo tengan claridad en cuanto a la situación que les resolvería sus problemas. Pero esto no implica que necesiten que alguien de fuera, verticalmente, propicie la consecución de dicha claridad. Lo que sucede es que pueden llegar a adquirir pistas cuando ven experiencias de similares que les son provechosas. Existen investigaciones que llaman la atención acerca de la existencia de un gran número de luchas y resistencias contra la explotación capitalista. Estas consideran que se trata de rebeliones contra la dominación en una insubordinación desde la cotidianidad. Aceptan que dichas expresiones conviven con la reproducción de relaciones de dominación y que persisten las relaciones instrumentales en la forma de muchas de esas luchas. También reconocen que tienen no pocas contradicciones, pero señalan que más allá de que en la vida cotidiana haya una gran gama de reproducción de las relaciones de explotación y dominación -que se dan cooptaciones, divisiones y disolución de resistencias-, se puede detectar asimismo que van creciendo en este ámbito los intentos de construcción de autonomías, de autogestión en la sobrevivencia, de autogobierno en comunidades y barrios, y de autorreflexión crítica en una dinámica anticapitalista. En este orden de investigaciones, hay otras que apuntan la existencia de experiencias que están dejando de reproducir el capitalismo. También hay conciencia de dichas resistencias anticapitalistas que se manifiestan de manera fragmentada y dispersa. Con todo, hay interactuaciones y se van dando variadas resonancias (Sandoval, 2014).

Teoría y DEBATE No. 62 
En los movimientos se fragua un proceso que al mismo tiempo debilita el orden existente y genera algo que pudiera llegar a ser totalmente otro modo de convivencia social. Los movimientos se desatan por un hartazgo ante situaciones que se perciben como intolerables. Uno de los cambios importantes es que mientras los movimientos tradicionales tenían regentes y jerarquías, los movimientos de los últimos años no toleran la división entre dirigentes y dirigidos, y tratan de ir hacia un horizontalismo sin líderes ni jefaturas. Muchos de los movimientos tradicionales tenían en la mente el Estado ante el que se protestaba o ante el que presentaban demandas. Pero últimamente hay movimientos que repudian las situaciones que tienen que ver con el capital y el Estado y, además, no los tienen como interlocutores. Así y todo, los poderes han ido aprendiendo de los movimientos para contrarrestarlos y para tratar de cooptarlos y manipularlos. Incluso hay ocasiones en que incitan a personeros para hacer pasar por movimientos lo que son presiones políticas cuyo objetivo es conseguir, mantener, afianzar y hasta recuperar la dominación cuestionada. Una constatación de lo anterior es que ningún movimiento disruptivo en sus primeras incursiones ha podido cambiar algún modo de producción. Esto solo sucede en los movimientos que se van engarzando en el largo plazo.

Podemos detectar que previamente a la aparición de movimientos hay un despojo desbocado. Cuando irrumpen los movimientos es porque se ha derramado un recipiente que acopiaba agravios. Entonces hay indignación y revueltas. ${ }^{3}$ A quienes se manifiestan se les quiere cooptar, pero como en las nuevas expresiones no hay líderes, a lo sumo voceros, esto se hace muy problemático. En ese momento

3. No hay que confundir la legítima indignación de los de abajo ante las injusticias con la mezquina indignación de los de arriba porque los de abajo externan su indignación, lo cual empeora, cuando ese arriba simula entender la indignación de los de abajo. 
Para seguir los rastros de los movimientos a inicios de la segunda década del siglo XXI

actúan los infiltrados para producir provocaciones. Antes había grupos que golpeaban e incluso masacraban a los manifestantes -como los llamados halcones del 71-, pero ahora hay grupos de provocadores que van a enfrentarse a las policías, para que estos puedan justificar su reacción y golpear no a los provocadores, sino a los manifestantes pacíficos y así aprisionar 'legalmente' a muchos de ellos. El propósito es meter a los movimientos en el desgaste de tratar de liberar a su gente. Evidentemente no todos los que responden violentamente son infiltrados, pues hay participantes que manifiestan su hartazgo explosivamente. Es por eso que la mayoría de los movimientos han visto la vía pacífica como una mejor táctica, lo cual es precisamente un estado que los poderes tratan de romper metiendo miedo, si no a los movimientos sí a la sociedad. ${ }^{4}$

En tanto otros sectores de la sociedad descubren que las demandas de los movimientos son sobre la vida cotidiana de la mayoría de la gente, incluyéndolos. Pero lo que no logra percibirse es que los movimientos no solo salen a las calles, sino que van construyendo nuevas formas de organización social, como sus asambleas, donde crean horizontalmente una democracia directa de discusión y de acción. Hay considerables repercusiones en la vida cotidiana de los participantes de los movimientos, las cuales se multiplica en otros ámbitos. Existe un abajo que se está moviendo de muchas formas, aunque muchas de ellas no sean perceptibles.

Aun así, tampoco hay que dejar de ver que no todo lo de abajo se rebela contra la opresión, la dominación y las diversas formas de explosión y de exclusión que impone el capital. Todavía hay unas partes del abajo que están domi-

4. Para tratar de impedir la manifestación cívica de protesta muchos gobiernos han acudido a legislaciones que castigan a los manifestantes como la ley ciudadana española de finales de noviembre de 2013 , o los intentos mexicanos de cohibir las expresiones masivas. Son esas expresiones de totalitarismos invertidos que se quieren hacer pasar como democracias pero que atentan contra uno de los derechos fundamentales, el de manifestación.

Teoría y DEBATE No. 62 
nadas porque interiorizan la dominación y reproducen la vida capitalista en su diario acontecer. El abajo que sí se moviliza va mellando el poder y el capitalismo; sistema que se encuentra en su etapa terminal. En la vida diaria existe una amplia variedad de colectivos sin jefes, sin instituciones clásicas, que van debilitando la dominación, aunque esta se endurezca y criminalice a los movimientos sociales. No hay que perder de vista que en este largo periodo de crisis capitalista hay muchas bifurcaciones que se abren. Algunas salidas pueden ser peores que el antiguo sistema de explotación y dominación, pero hay formas alternativas que se van ensayando y que son embriones de otras modalidades de convivir solidariamente con lo humano y con la naturaleza.

De manera masiva en estos primeros años de la segunda década del siglo XXI por todo el mundo han aparecido movimientos originales impulsados por la indignación. Las protestas se enredan en lo electrónico y en las calles y plazas. Hay descontento con la democracia realmente existente, supeditada al despiadado despojo de un capitalismo en crisis. Es difícil poder apreciar la imagen de ese gran rompecabezas, porque sus piezas no son fijas sino fluidas. No hay un programa, porque los movilizados han roto el viejo esquema de movimiento. Lo que hay son muchas formulaciones que, en el fondo, apuntan al descontento con el mismo sistema capitalista. Hay una mundialización de la indignación. Los primeros logros de estos movimientos aparecen como insuficientes porque se mantiene la raíz del sistema capitalista, pero aunque se apacigüen temporalmente, han sido una escuela de nuevo tipo donde se han ido encontrando otras formas de hacer y de pensar: son embriones de protestas a punto de emerger en nuevas situaciones.

Si tratamos de ver las movilizaciones como un diálogo de los ciudadanos con los diversos poderes, podríamos deambular por un camino equivocado. La gente está hastiada 
Para seguir los rastros de los movimientos a inicios de la segunda década del siglo XXI

de lo que hacen esos poderes y lo manifiestan, pero para dialogar horizontalmente e iniciar nuevas búsquedas de convivencia. La izquierda y la derecha quisieran meterse en esas movilizaciones para aprovecharlas, pero las expresiones de abajo se han resistido a esas viejas manipulaciones, mientras diversos arribas los quieren reencauzar en la vieja forma de hacer política con algunos afeites. ${ }^{5}$ Los muchos abajos marcan otro rumbo y van construyendo otras formas de hacer política. Lo que se impone desde arriba, del signo que sea, se va socavando desde abajo paulatinamente hasta que eso que parecía sólido se cae como castillo de naipes sin sustento.

Pueden darse convergencias puntuales, pero no en todo, porque persisten los disensos y estos, más que condenables, son vivificantes. La unanimidad no puede ser el horizonte ni algo que convenza a una pluralidad muy diversa. La pregunta ante los indignados de todo tipo es por qué se rebelan. Hay quienes enfatizan que todas las revueltas son singulares, que en los momentos de rebelión la realidad antes aparentemente aceptada se cuestiona. Nos dicen que son momentos en que se suscitan acontecimientos capaces de poner a prueba la realidad y develar su fragilidad. Se hace inaceptable una realidad, porque se quiere construir otra. Se contribuye a plantear reivindicaciones colectivas sin que aplasten la dimensión de las expectativas de los sujetos. Se encuentran lenguajes donde se reconocen las propias experiencias. Cuando la gente se rebela va delante de los teóricos y de los políticos (Boltanski, 2013). Tanto se esfuerza el sistema por que se le rinda obediencia, sumisión

5. Habría que tener en cuenta que para una buena cantidad de personas lo electoral no está siendo respuesta. Aunque algunos personajes de las protestas estudiantiles chilenas consiguieron lo que se llama la bancada estudiantil, en estas mismas elecciones, donde la abstención fue la ganadora, muchos estudiantes de Chile llamaron en 2013 a no votar por el sistema.

Teoría y DEBATE No. 62 
y docilidad, que no soporta la rebeldía. Con todo, la rebeldía es una cualidad humana necesaria para vivir.

Hay muchas respuestas y debajo de ellas se encuentran otro tanto de supuestos que aluden a cómo debería ser la sociedad. Los que dicen que las rebeliones son por insatisfacción de los que tienen algo y quisieran más, o causadas por el resentimiento hacia los que sí tienen ese plus, demuestran una comprensión del mundo donde forzosamente debe haber poseedores y desposeídos, la desigualdad como algo deseable. ${ }^{6}$ Hay otras explicaciones que llaman la atención acerca de las rebeliones no son una irrupción momentánea, porque previamente al enojo ha habido una larga manifestación de varios descontentos. Por su parte, la gente siente que hay momentos de desafíos masivos; son las crestas de los movimientos. Lo que hay que destacar aquí es que se da una rebelión contra la desposesión de cualquier naturaleza.

En la investigación de la que partimos se destaca que los movimientos implican un conjunto de elementos que no se pueden ver como pasos o etapas de un proceso, sino como la amalgama del mismo proceso en el que surge el thimós (enfado, hartazgo, enojo) que desata el proceso, y en el que lo nuclear está constituido por la conjunción de diácope y aposyndeo (rupturas de diversas dimensiones transversales y varios niveles que producen desconexiones y desacoplamientos respecto al capital y al Estado) para generar una nueva construcción: la demiurgía (resquebrajamiento constructivo en otra dirección a la acostumbrada por el sistema). Mientras que la eureva (la incesante e incansable búsqueda) le da constante fluidez al conjunto.

Manuel Castells recalca que los movimientos de protesta están enredados no solo en Internet, sino en las redes de la sociedad; se gestan en Internet y se expresan en lugares 
Para seguir los rastros de los movimientos a inicios de la segunda década del siglo XXI

urbanos para hacerse visibles ante otros. Castells recuerda que una característica de Internet es la viralidad: hay contagios. La conexión que tiene reflexividad es exponencial en su crecimiento. La ocupación del espacio público para los manifestantes es central: al desarrollar redes no necesitan líderes; tienen dinámicas liberadoras; aparecen por chispas de indignación. Existe una transición de la indignación a la esperanza por medio de la deliberación comunitaria que tiene la característica de ser autónoma. Hay un espacio libre, autónomo entre Internet y el espacio urbano. Quienes se manifiestan se sienten unidos con otras personas. Superan los miedos al estar juntos en un espacio público. El autor resalta que en su origen los movimientos son siempre no violentos, aunque los quieran volver violentos. La discusión sobre la violencia entre ellos es una constante; no tienen una unidad ideológica. Pero sí tienen como proyecto común una nueva democracia, la cual viven en la red y en sus asambleas. Se trata de movimientos rizomáticos, que cuando surgen se van expandiendo. Lo rizomático no desaparece mientras existan las causas que lo generan. Y aunque decaigan, lo destacado es que estos movimientos producen cambios en las formas de pensar y hacer. Lo importante no es que el movimiento se organice, sino que las ideas se filtren en las paredes (sus pintas) y en las mentes. Su actuación va produciendo cambios. Emerge una oleada de movimientos sobre las ruinas de un sistema (Castells, 2013).

Muchos movimientos sociales están convencidos de que para acceder a otros mundos posibles donde imperen de veras la justicia, la libertad, la igualdad, el respeto a la vida misma y, por lo tanto, a la naturaleza, se requiere de la construcción de convergencias. Nada está predeterminado. Los grupos populares en búsqueda de otra política, sin perder su especificidad, sin caer en una estructura orgánica unificadora, se conectan, y organizan entre ellos

Teoría y DEBATE No. 62 
mutuas traducciones para poder entenderse. No se trata de una traducción lineal y vertical, sino horizontal e interactiva. Sus miembros reconocen una pluralidad de instancias epistemológicas. En esa dinámica van deambulando desde una posición ética de responsabilidad colectiva y de liberación solidaria. Se cuidan de no ontologizar situaciones coyunturales. Hay una deslegitimación del capitalismo, la cual se vive como una exigencia ética colectiva.

Esos grupos ensayan múltiples resistencias convergentes en la diversidad. Mientras la lógica del capitalismo neoliberal medra sobre el crecimiento de las desigualdades, los grupos populares en búsqueda de alternativas en su cotidianidad expresan reivindicaciones vitales, existenciales, culturales, y no solo económicas, políticas y sociales, aunque también las formulan. Intentan el predominio del valor de uso sobre el valor de cambio. En sus búsquedas enfatizan la posibilidad de la vida común respetando la sobrevivencia del planeta. Saben que nada tienen asegurado, pero se arriesgan y no quieren seguir viviendo atados al capital, a los poderes fácticos y al Estado. De que lo consigan depende que se logre una alternativa.

Las investigaciones que hemos estado realizando nos han hecho constatar la existencia de una pluralidad de agrupamientos y movimientos que ya no se plantean la toma del poder estatal, sino que buscan ponerse al margen del capital y del Estado para ir construyendo presentes que se consoliden en futuros viables, no asegurados, pero factibles. El movimiento que va en la dirección de emanciparse del Estado y del capital no será necesariamente masivo, visible, captable en una imagen. Cualquier sujeto colectivo, independientemente de su tamaño, de su visibilidad, si en su vida cotidiana erosiona al capital y al Estado se convierte por eso mismo en un movimiento que en algún momento podrá generar convergencias con movimientos de la misma naturaleza. También hemos detectado que estos 
Para seguir los rastros de los movimientos a inicios de la segunda década del siglo XXI

agrupamientos y movimientos han utilizado las convergencias para transmitirse experiencias y formas de reflexión para acciones similares en la búsqueda cotidiana de una autonomía desde abajo. Los movimientos sociales con sus innovadoras prácticas han ido rompiendo los moldes en que los académicos los hemos querido encerrar y van siendo lo que necesitan ser para transformar el mundo contra el que se rebelan y para crear otro mundo justo donde se viva la demoeleuthería. ${ }^{7}$

Si hacemos caso a Žižek, las sociedades tribales, preestatales, no obstante todos sus procesos de discusión auténticamente protodemocráticos (reunión de todo el pueblo, deliberación, discusión y voto colectivo) no son todavía democráticas. Žižek recomienda no pensar en volver a pasados. No obstante, esos pasados que subsisten y que se recrean en el presente con innovaciones pueden precisamente trasponer los límites de la democracia y llegar a situaciones mucho más liberadoras, como la demoeleuthería. Balibar (2010) acuñó el término égaliberté para destacar que todos los humanos son iguales en cuanto seres dotados de palabra y que la reivindicación de libertad-igualdad pone en jaque al orden prevaleciente. Stuart Hall (2010), invitando a manifestar el lugar desde donde se piensa, pues el pensamiento está moldeado por algún grado de posicionalidad, recomienda trabajar el adentro y el afuera; sostiene que lo simbólico es importante, pero advierte que no todo es discursivo, pues las relaciones sociales existen más allá de los discursos; apunta que los movimientos sociales

7. La demoeleuthería implica esa libertad de los de abajo que se reúnen, debaten, se dan instituciones no pesadas sino funcionales para remediar cuestiones prácticas, que cuando dejan de funcionar son cambiadas por el mismo procedimiento de debate, deliberación y decisión común de manera horizontal y sin jefes. Hemos seguido utilizando el concepto democracia para llamar esto, pero tal vez convendría atreverse a buscar nuevas formulaciones, porque donde quiera que se manifieste el kratos sale perjudicado ese demos, complejo y plural. 
provocan movimientos teóricos, y convoca a examinar las luchas ancestrales de los pueblos indígenas.

\section{Echar la mirada a un movimiento fundante} de nuevas modalidades

Se ha llamado la atención sobre la posibilidad de presentar demandas a los de arriba cuando parece que pueden darles respuestas positivas. No obstante, el poder siempre llevará a cabo solo lo que le conviene, por lo que es preferible ver como en los abajos societales hay muchas capacidades autónomas que van creando instituciones que reflejan un mundo nuevo donde irá imperando la democracia, la justicia y la libertad (Esteva, 2014). Si revisamos, estas dinámicas, observamos que provienen precisamente de la capacidad ejemplificante de un movimiento que ya lleva dos décadas de estar innovando.

Le Bot ha recalcado que desde la irrupción del zapatismo han pasado muchos años, y aunque los medios dominantes arguyan que se trata de un movimiento en decadencia, el zapatismo está más vivo que nunca. Se ha afianzado en el autogobierno. No se ha anquilosado, sino que se ha ido renovando continuamente. Hoy día ha ingresado en una nueva fase; una más colectiva. Le Bot recuerda que el zapatismo ha sido un movimiento precursor de los nuevos movimientos que funcionan en red y cuya gran fuerza consiste en buscar nuevos sentidos a la acción colectiva. Antes los protagonistas clásicos eran los partidos, los sindicatos, los Estados, pero hoy todo pasa por un compromiso personal antes que por organizaciones verticales; se busca una nueva forma de cultura política. El zapatismo con su constante práctica ha tenido influencia en este nuevo dinamismo, y evita la violencia como lo han hecho los participantes de la primavera árabe y del Ocupa estadounidense. 
Para seguir los rastros de los movimientos a inicios de la segunda década del siglo XXI

El zapatismo rompió con viejos eslogans y dogmas. Los movimientos indígenas llevan un paso lento pero constante. En cambio hay otros movimientos que suelen tener tiempos más limitados (Le Bot, 2014). En el mismo sentido Baschet (2014) enfatiza que el zapatismo es la autonomía y la distancia con el Estado. Dicha distancia está en la base de la reformulación de una perspectiva anticapitalista; misma a la cual han contribuido los zapatistas. Los quieren ver reducidos a unos municipios; no tienen en cuenta su influencia global. Los zapatistas han propuesto una organización político-social que no es capitalista y rompe las formas de vida en la que nos ha metido el capital. Su ejemplo ha sido vital para ver cómo no depender del mercado como único proveedor. Han ensayo una organización colectiva no estatal con la desespecialización de la política y la reapropiación de la decisión colectiva (Baschet, 2014).

En agosto de 2014 hubo un encuentro entre el EZLN y el Congreso Nacional Indígena (CNI) en uno de los caracoles zapatistas. Ahí se ejemplificó cómo se está construyendo la demoeleuthería. Los participantes del CNI sentían un compromiso con sus respectivas asambleas, las cuales estaban esperando los resultados de esta compartición. Un compartir de la experiencia que se entiende y se practica como la interlocución directa de comunidad a comunidad. Como no todas las comunidades pudieron asistir, se nombraron representantes de cada una para que estos escucharan, dijeran lo que se había acordado y regresaran a la comunidad a exponer lo sucedido en la compartición. Un elemento especialmente destacable fue la presencia de muchos jóvenes. Se dio la reunión y cada pueblo dijo su palabra y agradeció haber recibido el respeto de los demás. Todos hablaron y todos fueron escuchados.

En la compartición se propició, además, una convivencia. Compartieron experiencias, información y demandas. Hermanaron las luchas de resistencia y la rebeldía de los

Teoría y DEBATE No. 62 
pueblos; recopilaron información y vieron cómo resistían otros pueblos. Otro punto importante fue que cada uno de los pueblos participantes estaba resistiendo y sabía que había más pueblos en resistencia en el país. Al compartir cada situación se fue constatando la existencia de muchos problemas similares. Los pueblos comunicaron su historia, su experiencia de lucha, sus problemas con el gobierno, con el crimen organizado cómplice del gobierno. Palparon en la comunión los sufrimientos semejantes. Vieron que las políticas públicas del que llamaron mal gobierno eran para destruir a los pueblos, mientras que las luchas de los pueblos tenían como fin seguir viviendo. Denunciaron que los partidos y los gobiernos atentaban contra el agua, la tierra y la cultura de los pueblos originarios, pues había empresas trasnacionales que los estaban despojando de sus recursos y de sus tierras; les querían quitar todo. Se intensificó la preocupación por los despojos.

En esa compartición quisieron conseguir no solo el conocimiento mutuo, sino también la llegada a algunas conclusiones. Si bien sabían que no se podía emprender una estrategia definitiva, sí querían llegar a la aclaración de algunas ideas importantes para ver cómo detener el despojo. $\mathrm{Al}$ ir de por medio la vida de los pueblos, estaban dispuestos a no acatar las reformas neoliberales. Se alegraron por que en los hechos narrados y sentidos ellos se estaban encontrando, porque se sabían en una defensa amplia para poder seguir viviendo. Reflexionaron respecto a que esa defensa implicaba el propósito de que la gente recupere la libertad y tenga su propia justicia. Y buscaron unirse; captaron que estaban contra el capitalismo, pues este sistema es opresor de los pueblos. Los asistentes sabían que los resultados no serían inmediatos, pero confiaron en que serían favorables: formaron una esperanza. En la compartición surgieron cuestiones imprevistas, como la concurrencia de los jóvenes, como que las comunidades con presos políticos 
Para seguir los rastros de los movimientos a inicios de la segunda década del siglo XXI

hubieran optado por examinar este problema entre ellas. La demoeleuthería pudo irse fraguando porque en el CNI no hay dirección política jerárquica: es un movimiento horizontal, asambleario.

Los apuntes que hicieron las bases de apoyo del EZLN para su participación en la compartición con el CNI también dan pistas de la demoeleuthería. Una primera recapitulación de dichos apuntes destaca el hecho complejo de la resistencia (que se expresa en lo político, ideológico, económico, social y cultural). Se enfatizó que se resistía en la resistencia. Para las bases zapatistas su lucha no se queda en su localidad, ya que entienden que tiene un sentido más amplio y se proponen contribuir a la liberación de todo el pueblo de México; en pos de una nueva sociedad con su sistema de gobernar, donde el pueblo tenga verdaderamente la fuerza de mando y donde no sean unos cuantos los que manden con el resto obedeciéndolos.

El planteamiento principal de su práctica es el respeto a la madre tierra y la oposición a la destrucción de esta a manos del capitalismo que la quiere convertir en mercancía. Trabajan la tierra para cultivar la vida que ella les regala. Manifiestan la concurrencia de hombres y mujeres que se organizan para luchar por una nueva sociedad. Señalan que las armas de lucha son la rebeldía y la resistencia. Con la rebeldía dicen no al sistema que destruye, se oponen a las imposiciones, despojos y otras vilezas de los de arriba. Observan que la rebeldía nace de los pueblos y con ella es como dicen sí a sus modos de ir construyendo otro mundo con verdadera democracia, verdadera justicia y verdadera libertad. Recalcan que su libertad nadie se las ha regalado: la han conquistado ellos mismos. Con la resistencia saben que van construyendo una vida más justa.

Con su resistencia, los zapatistas van demostrando lo que es esa demoeleuthería: opinar, estudiar, analizar, proponer, discutir y decidir conjuntamente para el bien de todos. La 
compartición entre los zapatistas y los pueblos originarios del CNI ha llevado al reconocimiento de que el sistema capitalista es antidemocrático. Los zapatistas muestran que con su resistencia política han conquistado su libertad, pues son libres para gobernarse con el principio de mandar obedeciendo. Asimismo manifiestan su oposición al sistema capitalista que reprime y criminaliza a las organizaciones que luchan por la justicia, que da facilidades a los invasores trasnacionales, destructores de la madre tierra.

Los zapatistas se proclaman una organización anticapitalista. Han creado sus propios sistemas de elegir autoridades, de autogobierno, de justicia, de salud, de educación, de comunicación; también, las formas de producir y de trabajar la madre tierra. Toda esa experiencia que han ido acumulado construye esa demoeleuthería. Todo lo que hacen está aprobado por sus pueblos. Con su rebeldía y resistencia han decidido por sí mismos, colectivamente, en sus asambleas, el rumbo. Reconocen que se han enfrentado a situaciones duras, que han cometido errores, pero la autocrítica continua les ha ido permitiendo enmiendas progresivas. Además, son conscientes de que su experiencia no es algo idílico, y aceptan que pueden cometer nuevas equivocaciones; y no obstante, lo importante es la disposición que tienen, no de tratar de justificarlos, sino de detectarlos e intentar solucionarlos.

En la compartición expresaron que nadie va a luchar por ellos; que con su resistencia política saben cuándo y dónde aplicar la combinación de lucha; que distinguen entre la lucha violenta y la pacífica. También recordaron que al irrumpir públicamente hace dos décadas optaron inicialmente por la vía violenta, una determinación que duró solo unos cuantos días, pues el resto del tiempo han deambulado por la vía pacífica. Los zapatistas comunican que han descubierto un nuevo camino en la construcción del gobernarse sin liderazgo; enfatizan que su resistencia 
Para seguir los rastros de los movimientos a inicios de la segunda década del siglo XXI

política les dice que no deben rendirse, no deben venderse ni claudicar; que su resistencia ideológica les indica vivir comúnmente, con igualdad de decidir su vida de sociedad. Saben por larga experiencia que mientras en el sistema capitalista las decisiones las toman los criminales que están en el poder, el pueblo no decide ni tiene libertad de expresarse. Recapacitan que su resistencia política e ideológica les ha ayudado a imaginar cómo hacer el bien común y crearlo, como crear e ir a proponer a los pueblos. Se han concienciado de que tienen que resistir todo lo que venga del que denominan mal sistema.

Por su formación, los zapatistas resisten absolutamente a todo; se defienden con trabajos de resistencia, con reuniones, pláticas, folletos, películas, radios comunitarias y con sus propias canciones. Piensan que quien se rinde es un ser muerto, porque no lucha y no deja un camino bueno para la vida de sus hijos. Los zapatistas han mostrado en su escuelita abierta al mundo que gobiernan con autonomía, representando y sirviendo al pueblo, con puestos que no son para ganar dinero ni para dominar al pueblo. Han experimentado que con o sin dinero se puede gobernar, pues los que saben cómo es una buena justicia, una buena salud, una buena educación y una buena sociedad son precisamente los que padecen los sufrimientos de su falta. Están convencidos de que se necesita una rebelión organizada que sepa defenderse de la violencia del enemigo y que no permita que alguien aproveche el poder.

Para los zapatistas la resistencia económica implica pensar en una sociedad libre que tiene que ser planeada para no dañar la vida, es decir, una en la que se produzca la alimentación sin maltratar a la madre tierra. Se pronuncian contra el capitalismo, por ser un sistema de explotación y destrucción de la madre tierra, porque criminaliza las causas justas de los movimientos sociales. Se proponen sanear la economía, haciéndola anti-competitiva. En su

Teoría y DEBATE No. 62 
compartición, con una gran cantidad de ejemplos, hicieron ver que los zapatistas están construyendo, cambiando, corrigiendo, imaginando, reorganizándose y reeducándose al transformar las cosas malas por buenas. Una de estas tiene que ver con la justicia. Los zapatistas están por terminar con los liderazgos individuales en todos los niveles; dicen que con organización y unidad el pueblo puede hacer hasta lo que se ve imposible. Son conscientes de que están construyendo una pequeña sociedad que los ha salvado de la destructora sociedad capitalista, y de que en ella son de verdad independientes para decidir su gobernar en la autonomía del mandar obedeciendo. Recalcan, entonces, que son realmente autónomos, que hay derechos con igualdad, con verdadera democracia del pueblo.

Al tiempo, comparten que han tenido problemas por “propasados de democráticos y autónomos". Están construyendo una nueva cultura donde "pueblo manda, gobierno obedece". Han encontrado formas de vigilancia para que esto se mantenga y comunican que la nueva cultura así construida puede sintetizarse en frases cargadas de sentido y de expresión cotidiana como "manda el pueblo", "el gobierno es colectivo", "hay representantes, pero no líderes", "el pueblo crea su educación", "el pueblo cuida su salud”, etc. Con esta democracia los zapatistas crean su propia iniciativa en todos los campos para el bien común, sabiendo que todo trabajo debe ser para servicio del pueblo. No se cansan de señalar que en todos los planes de trabajo y en los terrenos de lucha se tiene que incorporar la resistencia; tampoco, de remarcar que cada iniciativa que se va creando va acompañada de la resistencia. En esta compartición llamaron la atención sobre las cambiantes formas de atacar que tiene el enemigo. $\mathrm{Y}$ es por esas que los zapatistas también tienen que cambiar sus formas de resistir. Destacan que han resistido hasta a 
Para seguir los rastros de los movimientos a inicios de la segunda década del siglo XXI

quienes han vendido su conciencia de lucha. Los zapatistas compartieron la historia que crean y recrean todos los días. ${ }^{8}$

Por otra parte, las comunidades autónomas siempre han estado atentas a lo que sucede en el país y en el mundo. A principios de octubre, los zapatistas participaron con veinte mil personas en las marchas nacionales de protesta contra la desaparición de los cuarenta y tres normalistas rurales de Guerrero, haciéndoles saber a los familiares de los desaparecidos que no estaban solos, que compartían su dolor y su rabia y que exigían también que se hiciera "justicia verdadera". ${ }^{9}$ Para la manifestación mundial de indignación, semanas más tarde, dieron a conocer un comunicado dirigido tanto a los condiscípulos, maestros y familiares de los muertos y desaparecidos de la escuela normal de Ayotzinapa como al pueblo yaqui, por el encarcelamiento de sus miembros a manos del Estado cuando estos defendían su derecho al agua.

Además, hicieron extensivo dicho comunicado al CNI y al mundo entero. Y anunciaron que, como parte de la jornada global del 22 de octubre de 2014, iluminarían la orilla de las carreteras cercanas a algunos de los caminos que sus pasos andan, así como caminos de terracería y brechas, en demanda por la presentación con vida de los 43 normalistas desaparecidos, el castigo a los responsables de los asesinatos y de la desaparición forzada, así como la exigencia de libertad incondicional para los dirigentes yaquis. De esta forma unieron su indignación a la de sus hermanos de Ayotzinapa y al pueblo yaqui. Manifestaron que aun cuando pequeña, esta luz suya era una forma de abrazar a quienes hoy hacen falta y a quienes su ausencia duele. Con la luz mostraron

8. Estos datos fueron sacados de las entrevistas y diversas secciones de la revista Rebeldía Zapatista, núm. 3, septiembre de 2014.

9. http://enlacezapatista.ezln.org. mx/20/4//0/07/comunicado-del-comiteclandestino-revolucionario-indigena-comandancia-general-del-ejercito-zapatistade-liberacion-nacional-mexico/

Teoría y DEBATE No. 62 
que no estaban solos en el dolor y en la rabia que vestían los suelos del México de abajo, porque con rabia y rebeldía $-\mathrm{y}$ no con resignación y conformismo- es como abajo se duele. Luego, convocaron al mundo entero a sumarse a esa jornada y terminaron demandando democracia, libertad y justicia. ${ }^{10}$

El 22 de octubre hubo expresiones de indignación masiva contra la desaparición de los jóvenes normalistas de Ayotzinapa al rededor del mundo. El enojo creció porque en la supuesta búsqueda realizada por el gobierno se descubrían numerosas fosas con otros asesinados. Se fue conformando un nuevo movimiento que no toleraba el destino que el neoliberalismo había asignado a esos jóvenes y así se respondió al desprecio de los arriba por la vida de los jóvenes pobres. Ese nuevo movimiento no ha aceptado que el Estado mexicano trate de dar soluciones simuladas y cínicas. ${ }^{11}$

Los zapatistas y el CNI difundieron una declaración conjunta, destacando que, desde los pueblos que eran, en sus luchas de resistencia y rebeldía y desde esa parte de este país que se nombraba el Congreso Nacional Indígena, enviaban su palabra-espejo a las víctimas, reunidos, porque el dolor y la rabia los llamaban y porque los estudiantes les dolían. Así, iniciaron su declaración, precisando que la desaparición de los cuarenta y tres normalistas secuestrados-desaparecidos por los malos gobiernos imponía una penumbra de luto, de zozobra y de rabia. Expusieron que la esperanza por la aparición de los compañeros era el dolor que los unía y la rabia que se hacía luz de la veladora que se movilizaba por todo el país llevando un grito de dignidad y de rebeldía en el México de abajo. No hubo confusiones en sus mentes; saben que mientras los criminales gobiernen

10. http://enlacezapatista.ezln.org.mx/20I4//0/20/el-ezln-se-une-a-la-jornadadel-22-en-apoyo-a-ayotzinapa-y-al-pueblo-yaqui/.

II. La primera página del periódico La Jornada del 23 de octubre de 2014 reportaba lo acontecido el día anterior con el siguiente titular:"Cunden protestas en México, EU, Europa y AL por el caso Ayotzinapa. Resuena la indignación". (http://www.jornada.unam.mx/2014//0/23/) 
Para seguir los rastros de los movimientos a inicios de la segunda década del siglo XXI

México, encabezados por el jefe supremo de los paramilitares, Enrique Peña Nieto, los que forjaban la consciencia ejerciendo y defendiendo la educación serán asesinados y desaparecidos, y los que defienden el agua para un pueblo heroico y milenario, como tribu yaqui, estarán en la cárcel. Denunciaron que el gobierno mexicano ha pretendido minimizar la criminal represión hacia los compañeros normalistas sosteniendo que se tratara de un acto más de la delincuencia organizada, acusación que han sostenido y reafirmado una y otra vez ante distintos casos y en diferentes regiones del país. Pero ellos señalaron que si bien los cuarenta y tres normalistas no significan más que unas cuantas muertes para los medios de comunicación, para ellos, para los pueblos que han sufrido la represión de múltiples formas, su desaparición es una reiteración de que los delincuentes están agrupados en todos los partidos políticos, ocupando puestos en las cámaras de diputados y senadores, en las presidencias municipales y en los palacios de gobierno.

Recalcaron que a los pueblos originarios se conduelen por Ayotzinapa. Los cuarenta y tres normalistas siguen desparecidos y el Estado hace como si ignorara su paradero, como si no fuera él quien se los llevó. Los de arriba pretenden desaparecer la conciencia, pero los desaparecidos han estado presentes en el pensamiento del país, en la mirada atenta y el corazón de los que son el Congreso Nacional Indígena. Además señalaron que en México hay peligrosas mafias que se hacen llamar Estado Mexicano. Los de arriba y su Estado hacen la guerra contra los de abajo; guerra en contra de los pueblos que luchan, en contra de aquellos que no han tenido rostro y que, para dejarlo más claro, se lo han arrancado, en contra de los que han sido los nadie, en contra de los que ven y sienten la violencia, en contra de los que sufren los ataques múltiples y simultáneos, en contra de los que saben que en México pasa algo malo, muy malo; una guerra que abajo se ve y se sufre en su totalidad.

Teoría y DEBATE No. 62 
Quienes hicieron este comunicado reiteraron que mientras no aparezcan con vida sus compañeros normalistas de Ayotzinapa, y en el estado de Sonora, sus hermanos Mario Luna Romero y Fernando Jiménez siguieran presos por defender el agua sagrada del río Yaqui; que mientras estuvieran secuestrados por los malos gobiernos, los pueblos originarios integrados en el CNI y los zapatistas continuarán respondiendo en consecuencia.

Aprovecharon para denunciar que no sólo en Guerrero, sino en todo el país, la represión en contra de los pueblos, el saqueo de los recursos naturales y la destrucción de los territorios era operado por el narco-Estado, el cual no tiene escrúpulos y usa el terrorismo para fabricar dolor y miedo, pues esa es su manera de gobernar.

Los zapatistas y el CNI proclamaron que ese dolor y rabia se ha convertido en dignidad y rebeldía en contra de la guerra de exterminio, pues lo contrario hubiera sido esperar la muerte, el despojo, más dolor y más rabia. El pronunciamiento terminó con la exigencia de la presentación con vida de los cuarenta y tres normalistas desaparecidos, de la liberación de los dirigentes yaquis encarcelados y del desmantelamiento de toda la estructura de Estado, sostén del crimen organizado. ${ }^{12}$

Este nuevo movimiento convergente, espontáneo, sin una estructura rígida, se ha volcado a las calles del mundo hastiado por un crimen de lesa humanidad cometido por el narco-Estado en México. Ese crimen revelaba la tragedia que viven los mexicanos, con una clase política podrida, en la cual ningún partido se salva, ya que todos intentaban

12. http://enlacezapatista.ezln.org.mx/20|4/I0/23/declaracion-conjunta-cni-ezlndel-22-octubre-20I4-nota-este-texto-fue-leido-por-miembros-del-cni-en-algunade-las-movilizaciones-que-se-realizaron-en-mexico 
Para seguir los rastros de los movimientos a inicios de la segunda década del siglo XXI

politizar el tema de acuerdo con sus cálculos electorales, olvidando la justicia y la reparación del daño. Las movilizaciones en México y en el mundo reclamaban que los desaparecidos sean regresados a sus casas con vida. Los zapatistas primero marcharon en silencio y después se manifestaron con velas encendidas, porque el silencio es mucho más fuerte y contundente para acusar a los de arriba e interpelar a los de abajo; también, para empezar a buscar por otro lado formas diferentes de hacer política. Las marchas, manifestaciones, plantones y diversas expresiones de repudio declaran un total desacuerdo con lo que están haciendo los de arriba.

Se encienden luces para buscar - desde abajo, en los colectivos, en la vida cotidiana- cómo irse zafando del imperio tan desastroso del capital y del Estado, que no tiene respeto por la vida. Ese nuevo movimiento se opone al mensaje encerrado en ese acontecimiento que mostró que los jóvenes no tienen cabida en este país y, por eso, se les debe desaparecer y masacrar. Ese hecho demostró que ser joven se ha convertido en algo terrible: es estar en peligro de muerte. Los de arriba, con sus continuos crímenes cotidianos quieren inocular a la gente para que crea que eso es normal, pero el nuevo movimiento hace ver que una gran parte no se ha dejado cegar por el veneno estatal ni está de acuerdo con la situación de un narco-Estado.

El nuevo movimiento apunta a la existencia de muchos jóvenes que están en busca de "otro mundo". Entre los veinte mil zapatistas que marcharon, la mayoría eran jóvenes. Hay muchos colectivos en las ciudades y en el campo que están buscando otras formas de convivencia, nuevas formas para decidir cómo hacer sus vidas, cómo ponerse al margen del capital y del Estado, cómo resolver sus propias necesidades con creatividad e imaginación.

Teoría y DEBATE No. 62 


\section{A manera de cierre}

Hasta aquí hemos atisbado que pululan por todas partes agrupaciones pequeñas que de miles de maneras resisten la explotación, la opresión, la dominación; que hay movimientos que surgen ante situaciones intolerables que multiplican una chispa a partir de algo aparentemente circunstancial; que hay resonancias en otros; que los grandes movimientos consiguen impactar en más personas y concitar la indignación; que vienen nuevas resistencias en pequeños núcleos, pero multiplicadas y convergentes con otras. Los poderosos piensan que criminalizando la protesta (penalizando con cárcel y exageradas multas las manifestaciones públicas de desacuerdo) pueden controlar el descontento, pero, por más posiciones autoritarias y absurdas que impongan, la gente encuentra formas de construir al margen del poder.

Es cierto que todos los movimientos sufren una desgastante entropía, y que muchos se van apagando lentamente o que otros tantos fenecen como viejas estrellas engullendo lo que tienen cerca, pero también lo es que nuevas modalidades aparecen y aparecerán mientras haya reclamos de diversa naturaleza. No se trata de algo cíclico ni repetitivo, sino de una expresión en espirales asimétricas. Los movimientos tienen momentos disruptivos muy visibles, sin embargo hay dinámicas fluidas de diferentes intensidades y de difíciles percepciones. Así, transmutan de expresiones materiales, de energía manifiesta, a situaciones similares a las de la energía oscura. De esta manera, los movimientos no tienen siempre las mismas formas, sino que evolucionan, y no de manera lineal, sino con intermitencias y hacia modalidades novedosas y alternas, rompiendo con toda visión mecanicista y esencialista, porque en el fondo estos dependen de las voluntades, las sensibilidades y las imaginaciones creativas.

Analíticamente se ha llegado al establecimiento de una distinción entre movimientos sociales (todos los que de 
Para seguir los rastros de los movimientos a inicios de la segunda década del siglo XXI

alguna manera protestan por las injusticias del capital y del Estado) y movimientos emancipatorios (los que han comprendido que más vale deambular al margen del capital y del Estado para ir formando otro tipo de sociedad con justicia, democracia y libertad). Con todo, los límites no son tan tajantes en las luchas de los de abajo. Los combates de los trabajadores por mejorar sus salarios y condiciones de vida se han visto como integrados a la lógica capitalista. No obstante, esas luchas también atentan contra el mantenimiento de las relaciones de producción capitalista. Es por eso que el neoliberalismo ha disminuido los salarios y ha procurado desmantelar las prestaciones sociales conseguidas en los movimientos obreros de décadas anteriores. Esas luchas son más complejas, pues interpelan al capital y debilitan los niveles de explotación y de dominio. Las respuestas, tanto del capital como del Estado, a las luchas de los de abajo pudieran interpretarse como la tendencia a conseguir un nuevo equilibrio que mitigue el conflicto. Esta es la visión de los explotadores y los dominadores; no obstante, el conflicto subsiste y se larva o mantiene latente.

Otra consideración tiene que ver con luchas de los movimientos sociales que son derrotadas. Y esto puede ser en lo coyuntural, pero las luchas que no triunfan no necesariamente deben considerarse derrotas para los de abajo, sino contribuciones a sus experiencias y fisuras a la dominación. Las heridas que estas producen al sistema no son únicamente en partes localizadas, sino en la dinámica de la propia relación capitalista.

De la misma forma, las luchas de los movimientos que interpelan al Estado tampoco pueden reducirse a la óptica del reforzamiento estatal. Cuando de alguna manera avanzan las propuestas de los de abajo, el Estado cede espacios; cuando los de abajo captan que sus demandas no son atendidas, o que la solución es parcial y no de raíz, van captando la incapacidad estructural estatal para

Teoría y DEBATE No. 62 
responder verdaderamente a sus necesidades. Podría ser que las luchas masivas amainen e incluso se aplaquen en determinados tiempos, pero tal apaciguamiento no implica la finalización del descontento, sino la previsión de que este volverá a manifestarse de otras maneras.

Una visión desde abajo permitirá percibir que se trata de un conjunto de luchas de larga duración que no son estáticas, sino cambiantes, y que esto puede favorecer las búsquedas de alternativas. Algunos se preguntan para qué sirven las manifestaciones masivas de descontento si lo que se consigue con ellas es poco, nada o represión. Sin embargo, son ellas las que han estado sirviendo para que los de abajo se vayan reconociendo, para que vayan dialogando entre sí y vayan permitiendo resonancias de diversas experiencias libertarias. Podría parecer que las múltiples luchas que se dieron en el mundo durante 2011 no llegaron más allá de una exteriorización de hartazgo. Sin embargo, han aparecido nuevas luchas que van consolidando una tendencia entre los de abajo: la detección del origen de sus males en el sistema capitalista en conjunto.

Fecha de recepción: 27 de octubre 2014 Fecha de aceptación: 03 de noviembre 2014

Bibliografía 40
Adame, Miguel Ángel (2013)."Reseña de Repensar los movimientos sociales de Jorge Alonso". Disponible en http:// www.rebelion.org/noticia.php?id= 177528.

Alonso, Jorge (20I3). Repensar los movimientos sociales. México: CIESAS.

Alonso, Jorge y Juan Manuel Ramírez (comps.) (1996). La democracia de los de abajo en Jalisco. Guadalajara: CIESAS. (1997). La democracia de los de abajo en México. México: Centro de Investigaciones Interdisciplinarias en Humanidades, UNAM. 
Para seguir los rastros de los movimientos a inicios de la segunda década del siglo XXI

Arditi, Benjamin (2014, septiembre). La comunicación distribuida: la imagen de pensamiento de la totalidad y las insurgencias virales. Conferencia presentada en la Universidad de Guadalajara, Guadalajara.

Balibar, Étienne (20I0). La proposition de l'égalité. París: PUF. Bauman, Zygmunt (2013). “Es necesaria una nueva batalla cultural”, Nueva Sociedad, 247, pp. 8I-89.

Boltanski, Luc (20I3).“¡Por qué no hay revueltas? ¿Por qué hay revueltas?". Disponible en http://vientosur.info/spip. php?article8489

Calle, Ángel (2013). "Brasil, de los jóvenes iracundos a los nuevos rebeldes". Disponible en http://desinformemonos.org/20 I3/I I/brasil-de-los-jovenes-iracundos-a-losnuevos-rebeldes/

Castells, Manuel (20I2). Redes de indignación y esperanza. Madrid:Alianza Editorial.

(20I3, noviembre). Enredados para la libertad. Movimientos sociales en la era de Internet. Conferencia magistral en la cátedra Jorge Alonso, Guadalajara.

Cerdá, Paco (20I3). “Entrevista a Peter Burke”. Disponible en http://www.laopinioncoruna.es/contraportada/20 I $3 /$ I I/06/

Esteva, Gustavo (20I4).“Capacidad de respuesta”. Disponible en http://m.jornada.com.mx/index.php?articulo=02 0 2pol\&seccion=opinion\&amd $=2014 \mathrm{I} 0 \mathrm{I} 3$

Fábregas,Andrés (20I4), “Repensar los movimientos sociales”, Espiral, XX(60), pp. 23I-237.

Gago, Verónica (20|4). "Entrevista a Jérôme Baschet". Disponible en http://www.rebelion.org/noticia_pdf. php?id=190780.

González Casanova, Pablo (1997).“¡Por qué la democracia de los de abajo?", en Jorge Alonso y Juan Manuel Ramírez (coords.) (1997), La democracia de los de abajo en México (pp. 9-13). México: Centro de Investigaciones Interdisciplinarias en Humanidades, UNAM.

Teoría y DEBATE No. 62 
Bibliografía

Hall, Stuart (2010). Sin garantías: trayectorias y problemáticas en estudios culturales. Popoyán, Colombia: Envión Editores. Hernández, José Luis (20|4). "Apuntes sobre la lucha estudiantil en el Instituto Politécnico Nacional". Disponible en http://www.rebelion.org/mostrar. php?tipo=5\&id=Jos\%E9\%20Luis\%20Hern\%EIndez\%20 Ayala\&inicio $=0$

Le Bot,Yvon (20I4). “El zapatismo es un movimiento esencial". Disponible en http://www.pagina / 2.com.ar/diario/ elmundo/4-257756-20I4-I0-I8.html

Moreno, José Luis (20I4). "Los movimientos sociales funcionan de manera autorreferente, como los partidos". Disponible en http://www.rebelion.org/noticia. php?id= 190020

Rodríguez Araujo, Octavio (20I4). "Incógnitas sobre los movimientos sociales". Disponible en http:///www. jornada.unam.mx/20 I4/ /0/02/opinion/023al pol

Sandoval, Rafael (20I4)."Contrainsurgencias y resistencias anticapitalistas. Repensar nuestra práctica política”, en Armando Rentería Castillo, Jesús Zamora García, J.A. Castañeda Arellano, Jorge Regalado Santillán, Rubén Martín Martín, Rafael Sandoval Álvarez y Marcelo Sandoval Vargas (20I4), Más allá de la decepción y la utopía: resistencias antiautoritarias en Jalisco (1968-20/3) (pp. 155-199). Guadalajara: Grietas Editores.

Tischler, Sergio (20I3). Tiempo y emancipación. Oaxaca: El Rebozo.

Touraine,Alain (1987). Actores sociales y sistemas políticos en América Latina. Santiago: PREALC.

Yacubovich, Gabriel (20I3). “Entrevista a Raimundo Viejo”. Disponible en http://www.rebelion.org/mostrar. php?tipo $=5 \&$ id $=$ Gabriel\%20Yacubovich\&inicio $=0$ 